\title{
NILAI ESTETIKA TARI DAMPENG PADA MASYARAKAT MUARA PEA DESA BUKIT HARAPAN KABUPATEN ACEH SINGKIL
}

\author{
LINDA NOVALIA SIHOTANG \\ Prodi Pendidikan Tari
}

\begin{abstract}
ABSTRAK
Dampeng dance is a dance that tumbuhdanberkembang in Aceh Singkil. Dampeng customary sudahpadatahun inimerupakantarian 1986. The purpose of this study is to discuss the dampeng dance from the perspective of aesthetic value.

The theory used in this research is the aesthetic theory of Dhrasono which contains about: motion, fashion poetry and music. This theory is a reference to strip existing problems in Dampeng dance.

When the study to discuss Dampeng dance performed during the three months, from mid-December 2015 to February 2016. The research in the village of Bukit Harapan. Subdistrict Gunung Meriah. The population is two persons namely speakers and artists, who know about the culture Singkil. Samples are numbered two people are a resource and artists in the district of Aceh Singkil.Teknik data collection include observation, interviews, literature study and documentation.

Dampeng aesthetics of the dance are the motions of martial that have governance rules, the satisfaction score and the value of togetherness for the people of Aceh Singkil. Having yangtinggi excellent value for people who feel that the dance Singkil Dampeng is partly art and cultural preservation is still there and is still known to the public sampek Aceh Singkil. Dance dampeng also has aesthetic in fashion is clothing with the colors of firm and soft, the color of clothing also has character. It's all evidence of their love of their culture. Of these colors Singkil community admire and maintain Dampeng dance clothing for use by generations to always be worn when dancing.
\end{abstract}

Keywords: Aesthetic value, Dancing Dampeng, Aceh Singkil 


\section{PENDAHULUAN}

\section{A. Latar Belakang Masalah}

Aceh adalah sebuah propinsi di Indonesia. Aceh terletak di ujung pulau Sumatera dan merupakan propinsi paling Barat di Indonesia, administratifnya adalah Banda Aceh. Masyarakat Aceh terdengar sangar religius, memiliki budaya berlandaskan Islam. Kehidupan kebudayaan (adat) Aceh dengan Islam tidak dapat dipisahkan harmonisasi antara adat dan Islam ini berkembang berbagai aspek kehidupan masyarakat. "Kebudayan adalah sistem gagasan, tindakan dan hasil karya manusia dalam kehidupan masyarakat yang dijadikan milik diri manusia dengan belajar".Maka disimpulkan kebudayaan adalah hasil dari karya cipta, dan rasa yang merupakan suatu kebiasaan yang integritas, dimiliki oleh manusia mencakup pengetahuan, kepercayaan, kesenian, moral, hukum, adat istiadat yang mempunyai sifat dinamis, artinya perubahan mengikuti setiap perkembangan daya nalar manusia. pengajarannya yang diwariskan dari mulut ke mulut (oral tradition) (Nettl 1973:3). Dengan demikian pewarisan kebudayaan melalui mulut ke mulut dapat menciptakan hasil kebudayaan musik yang berbeda dari setiap generasi.

Tari dampengini merupakan tarian adat di wilayah Aceh Singkil. Bila manaada suatu pesta tanpa dihibur atau dibuka dengan tari dampeng sepertinya acara pesta tersebut kurang sempurna dan tari ini merupakan bagian dalam setiap acara pesta pernikahan dan khitanan. Tari ini dilakukan beramai-ramai untuk menghibur tamu yang datang, para penari membentuk lingkaran dan mengelilingi tamu-tamu yang datang ke acara tersebut. Didalam tarian ini (dampeng)Aceh Singkil terdapat syair yang mengiringi sebagai musik. Tari dampeng diartikan pembukaan (mukaddimah) tari, dimana tari ditampikan pada acara pembukaan.Seiring berkembangnya zaman tari ini banyak digunakan dalam pertunjukan, serta pesta perkawinan, khitanan, penyambutan tamu dan 
sebagainya. Untuk mengetahui lebih dalam lagi tentang tari dampeng penulis tartarik untuk meneliti tantang “ Nilai Estetika Tari Dampeng pada Masyarakat Muara Pea Desa Bukit Harapan Kabupaten Aceh Singkil ".

\section{B. Identifikasi Masalah}

1. Bagaimanakah nilai estetika tari Dampeng pada masyarakat Muara Pea Kecamatan Bukit Harapan Kabupaten Aceh Singkil?

2. Bagaimanakah nilai tari Dampeng pada masyarakat Aceh Singkil?

3. Bagaimana tari Dampeng pada masyarakat Muara Pea Kecamatan Bukit Harapan Kabupaten Aceh Singkil?

\section{Pembatasan Masalah}

1. Bagaimanakahbentuk Tari Dampeng Pada Masyarakat Aceh Singkil?

2. BagaimanakahNilaiEstetika Tari Dampeng Pada Masyarakat Muara Pea Kecamatan Bukit Harapan Kabupaten Aceh Singkil?
D. Perumusan Masalah"Nilai Estetis Tari Dampeng Pada Masyarakat Muara Pea Kecamatan Bukit Harapan Kabupaten Aceh Singkil "?

\section{E. Tujuan Penelitian}

1. Untuk mendeskripsikan bentuk tari Dampeng pada masyarakat desa Muara Pea Kecamatan Bukit Harapan Kabupaten Aceh Singkil.

2. Untuk mendeskripsikan nilai estetika tari Dampeng pada masyarakat desa Muara Pea Kecamatan Bukit Harapan Kabupaten Aceh Singkil.

\section{F. Manfaat Penelitian}

1. Analisa yang dilakukan dapat membantu untuk mengetahui bagaimana tari dampeng di Aceh Singkil.

2. Sebagai bahan motivasi bagi setiap pembaca,khusus generasi muda dan masyarakat di Aceh Singkil.

3. Sebagai sumber informasi mengenai kesenian yang terdapat di Aceh Singkil. 
4. Dapat bermanfaat untuk mengantisipasi agar kesenian dan nilai estetika tari dampeng menjadi identitas dari Aceh Singkil.

5. Sebagai referensi semua pihak yang hendak meneliti kesenian ini lebih dalam yang membangun kebudayaan khususnya dibidang seni tradisional.

6. Sebagai referensi bagi mahasiswa dan mahasiswi program Seni Tari di Universitas Negeri Medan.

\section{Teori Bentuk}

Menurut Langer (1978:1516) mengungkapkan bahwa Bentuk adalah struktur artikulasi sebuahhasil kesatuanyang menyeluruh dari suatu hubungan berbagai faktor yang saling berkait. istilah penyajian sering didefinisikan cara menyajikan ,proses pengaturan dan suatu pementasan.

\section{Teori Estetika}

Dharsono (2007:6) "Estetika berasal dari bahasa yunani kuno aesthetom, yang berarti kemampuan melihat lewat pengindraan, atau persepsi perasa, pengalaman, pemandangan".

\section{A. Lokasi dan Waktu Penelitian}

\section{Lokasi Penelitian}

Lokasi penelitian dilakukan di Kecamatan Gunung Meriah, Aceh Singkil dan Desa Muara Pea. Pemilihan tempat ini dikarenakan tempat ini tari dampeng masih dijalankan, dan masih dilestarikan oleh Seniman setempat.

\section{Waktu Penelitian}

Penelitian dilakukan bulan Desember sampai bulan Maret 2015.

\section{B. Populasi}

maka yang akan menjadi populasi adalah tokoh-tokoh budaya masyarakat yang mengetahui tari dampeng yang berada di Aceh Singkil, seniman Singkil mengetahui tentang tari dampeng dan beberapa para masyarakat di Muara Pea 


\section{Teknik Pengumpulan Data}

\section{Observasi}

Untuk mendapatkan data-data yang diperlukan, penulis akan melakukan observasi secara langsung karena bertujuan untuk mengetahui bagaimana sebenarnya tari dampeng pada masyarakat Aceh Singkil.

\section{Wawancara}

penulis sebagai pemberi pertanyaan dan narasumber sebagai jawaban.

\section{Dokumentasi}

Kamera yang digunakan adalah samsung Galaxi S3mini GT 18190, kamera 4MB.

\section{Studi Pustaka}

1. Nila Wahyudi Lubis, dalam skripsinya yang berjudul “ Eksitensi Dan Makna Simbolik Tari Dampeng Dalam Upacara Adat Sumando Pada Etnis Pesisir Tapanuli Tengah Sibolga".Skripsi ini menambah wawasan dan sebagai pembanding mengenai dampeng agar penulis mengetahui lagi tentang tari dampeng yang ada di Pesisir Sibolga.

2. Riska Zunianda, 2015 judul skripsi "Etika Dan Nilai Estetika Tari Rapa'i Geleng Pada Masyarakat Aceh Barat Daya" Tulisan ini sangat berperan bagi peneliti sebagai penambah wawasan, informasi dan sebagai pembanding mengenai keberadaan.

3. Haryati Hutoari, 2012 judul skripsi "Fungsi Dan Makna Gerak Tari Rampoe Aceh Pada Masyarakat Kota Langsa” yang membahas tentang fungsi, makna, dan sejarah tari rampoe Aceh. Skripsi ini membahas tentang fungsi dan maksa sehingga dapat membantu penulis dalam menyelesaikan skripsi.

4. Purba Ana, 2014. Judul skripsi “ Analisis Musikal Dampeng Pada Upacara Adat Perkawinan" Medan : Universitas Sumatera Utara. Tulisan ini membahas tentang musik dan upacara adat, tulisan ini sangat membantu penelitian dan melengkapi pengumpulan data yang 
berhubungan

dengan

permasalahan kebudayaan tari dampeng yang diteliti.

5. M. Jakfar Puteh dalam jurnalnya berjudul " Sistem Sosial Dan Budaya Masyarakat Aceh: Islamic Studies Jurnal”. 2013 Tulisan ini juga membahas tentang sosial budaya masyarakat aceh. Tulisan ini sedikit banyak membantu saya bagaimana sikaf orang aceh di zaman dahulu dan dimasa sekarang.

\section{Teknik Analisi Data}

\section{Geografi Kecamatan Singkil}

\section{Sistem Religi}

Tentang agama penduduk Singkil, bahwa umumnya masyarakat Singkil beragama Islam, dan sebagian kecil memeluk agama Kristen, yang terletak di daerah Simpang Kanan di desa Kuta Kerangan.

\section{Kesenian}

Labehatan, Dampeng, Siwah, Tari Sri Ndayong, Tari Piring, Tari Biahat (Tari Harimau), Tari Payung, Tari Lelambe.

\section{Asal Mula Tari Dampeng}

Tari Dampeng berasal dari seorang pendatang yang berasal dari Minangkabau untuk berdagang ke Singkil, dan menetap di Singkil. Tarian ini merupakan salah satu tarian pembuka pada masyarakat Suku Singkil. Tari ini pertama kali ditarikan pada tahun 1986. Singkil banyak didatanagi berbagai etnis misalnya, pak-pak, karo, jawa, gayo, alas dan minangkabau. Migrasi etnis ini lebih di dorong oleh faktor dagang. Orang Padang terkenal sebagai pedagang ulung dan gigih. Banyak perdagang membawa barang kebutuhan penduduk yang diminati oleh masyarakt singkil. Orang Minangkabau, alas pak-pak dan jawa lebih banyak datangi dan menetap di wilayah singkil sekitar pantai (laut).

Budaya orang padang yang dibawa oleh pedagang-pedagang yang datang ke wilayah Singkil ikut menyatu dengan kebudayaankebudayaan setempat, sehingga menghasilkan kebudayaan yang unik, tidak sama dengan kebudayaan asli yang dibawa oleh etnis-etnis yang datang ke wilayah Singkil. 
Perkawinan yang menurunkan generasi penerus telah membaurkan penduduk orang Singkil dengan penduduk lainnya. (Yunus, Ahmad. 1986:100)

\section{Gerak}

Dalam tarian dampeng Ada beberapa ragam yang terdapat menggunakan tenaga yang banyak dan waktu yang tidak terlalu lama, sehingga tarian yang dihasilkannya cepat tetapi membutuhkan tenaga, sebagaimana gerakan silat gerakan dalam dampeng ini diantaranya adalah dengan gerakan kaki dan tangan yang cepat dan membentuk lingkaran.
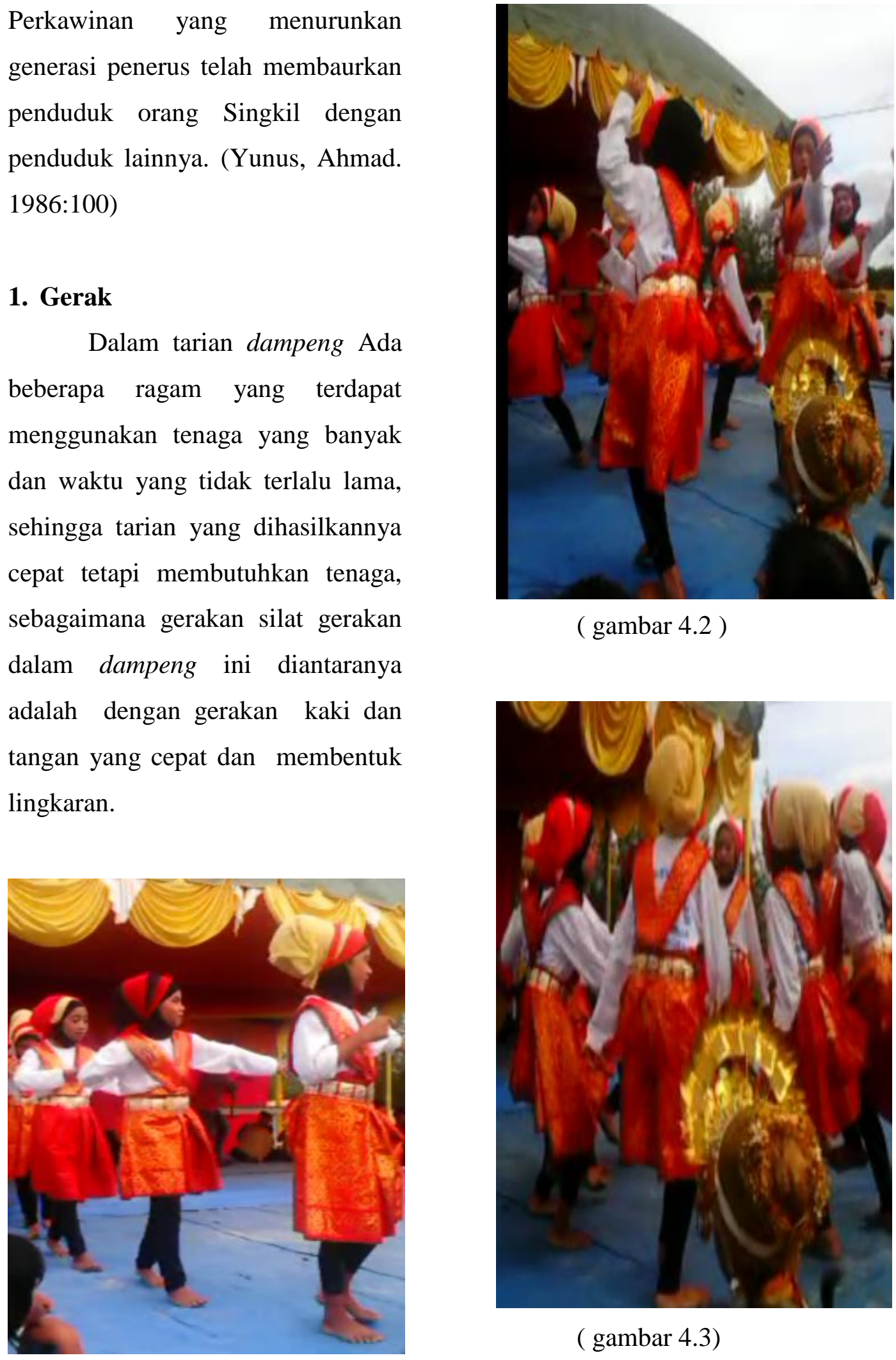

( gambar 4.2 )

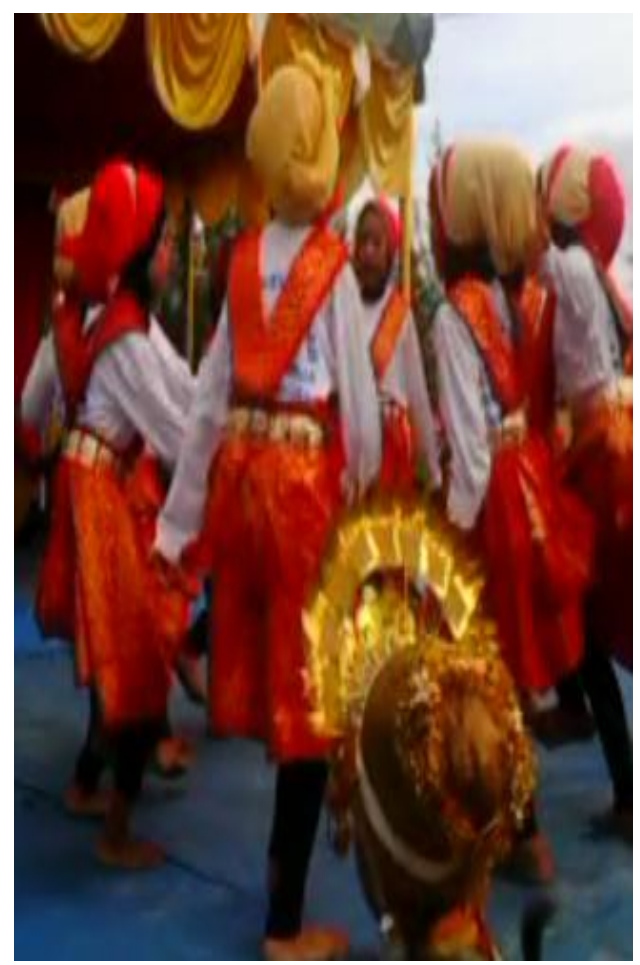

( gambar 4.3)

( gambar 4.1) 


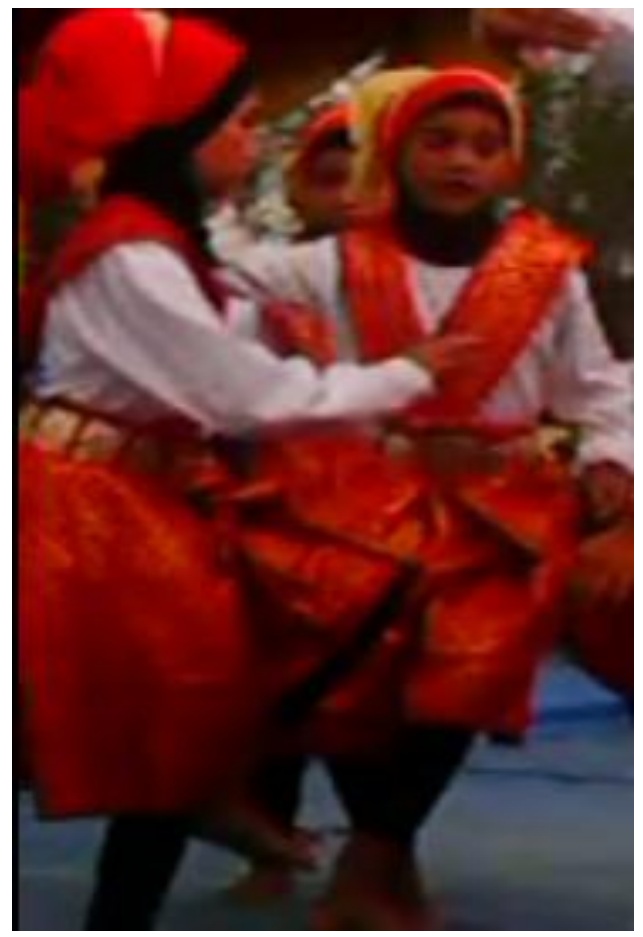

( gambar 4.4)

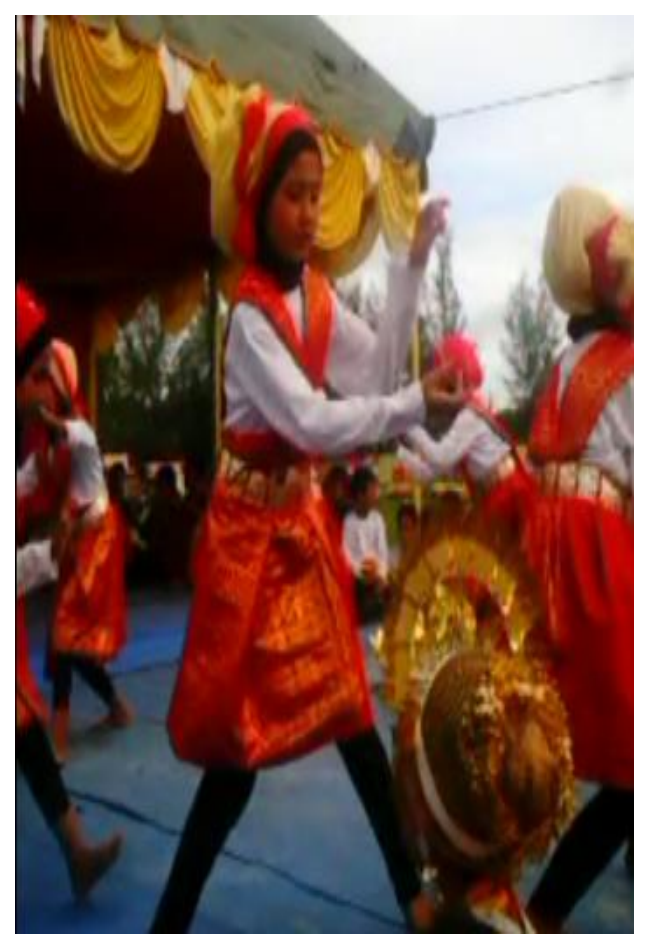

( gambar 4.5)

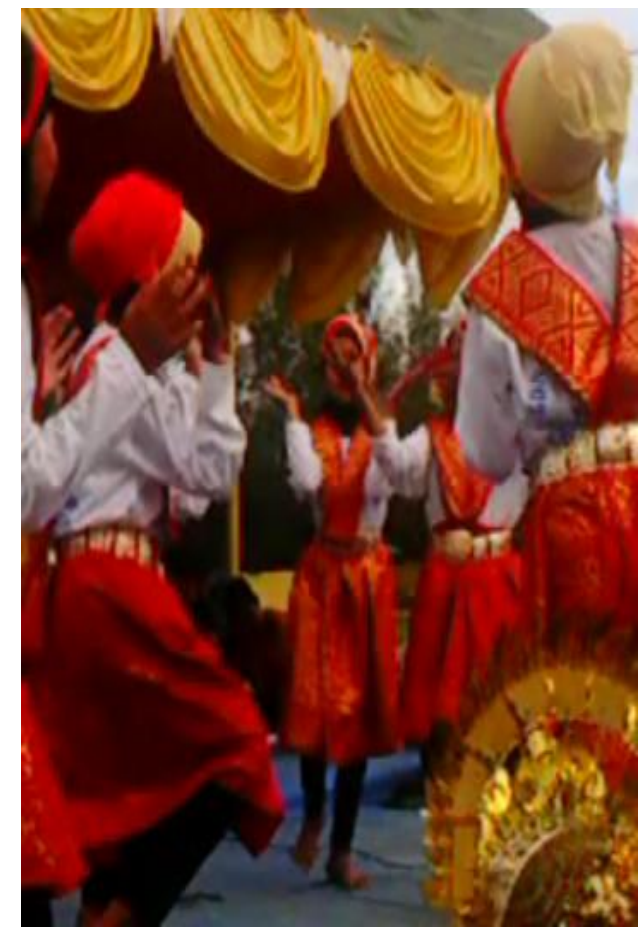

( gambar 4.6 )

\section{Pola Lantai}

Pola yang digunakan dalam tarian ini ialah membentuk lingkaran.

\section{Busana}

Busana yang digunakan penari pada dampeng terdiri dari baju tangan panjang warna putih, celana panjang warna hitam atau putih, kain sarung setengah tiang (disebut lunggi), dan attribut lainnya seperti tali pinggang, tutup kepala (sebelit pinder) dari kain persegi empat yang dilipat dan diikat keliling kepala. Sedangkan salah 
Gesture

satu topinya mencuat ke atas, di bagian belakang kepala. Dalam busana tari Dampeng memakai perpaduan beberapa warna yang dikenakan yaitu warna putih (yang melambangkan kesucian), hitam (yang melambangkan ketegasan), merah (yang melambangkan keberanian), kuning (yang melambangkan perdamaian).

\section{Musik}

Dalam tari dampeng musik yang digunakan adalah musik tradisional dan syair.

Hayo....hayoo yayo hoooo Da gak allah ho are are Hayo..... hayoo yayo hoooo Hanya allah ho are are are

Ade nak minyath

(dua kali Pengulangan)

Ada masanya

Ade nak minyath Kisath dampeng

Belen pe lae alas Taru na nina

Ada masanya kisah dampeng

Dahulu di hutan tempatnya tuan
Slameth nolam ken lai surhaya

Tah loh dampeng Lae surhaya

Selamat untuk kita semua

Kisah dampeng kita semua

Dek nak minyath are Kisah dampeng

Balen ate dibanyath nina

Kadeh ke malam tukrang

Impai simat mat tana

Ada masanya are kisah dampeng

Sekarang dibawa tuan

Saat malam turang

Impian di mata-mata

Tari dampeng ualang tading

Tari dampeng kesenian ta

Tari dampeng ulang rapanmu

Tari dampeng nan lupakan

Tari dampeng ini sekarang

Tari dampeng kesenian kita

Tari dampeng harapanmu

Tari dampeng tidak terlupakan 

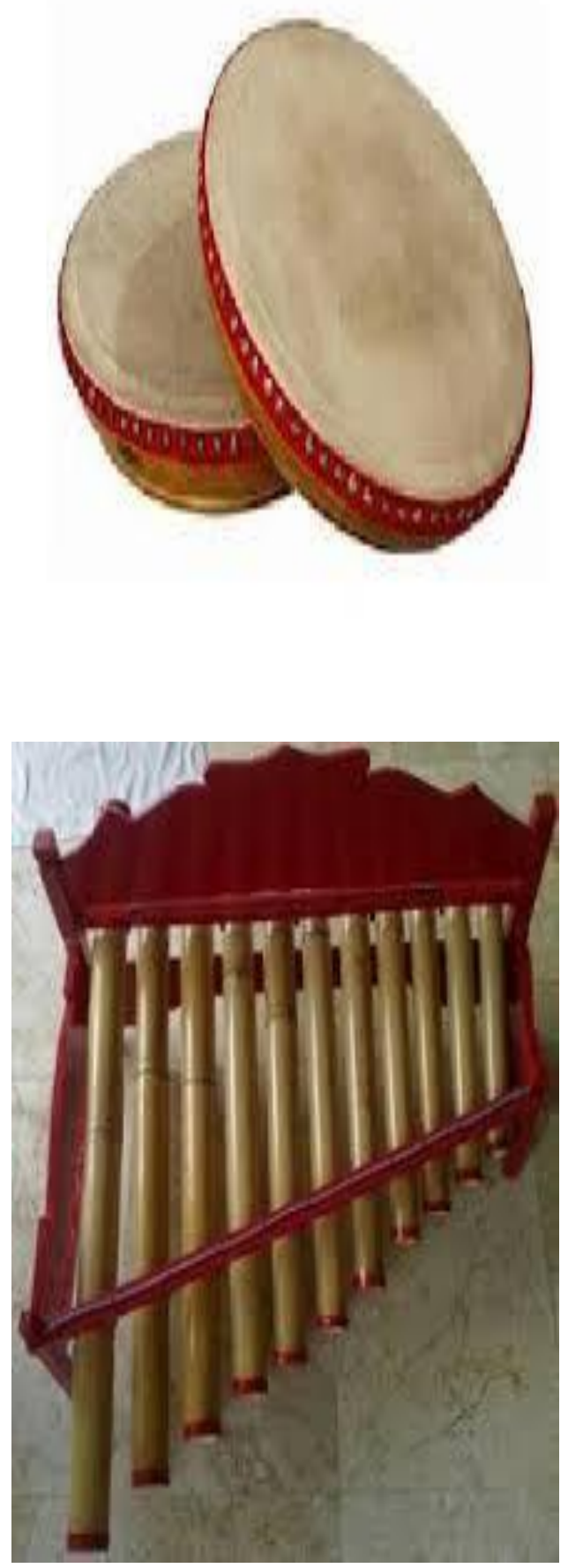

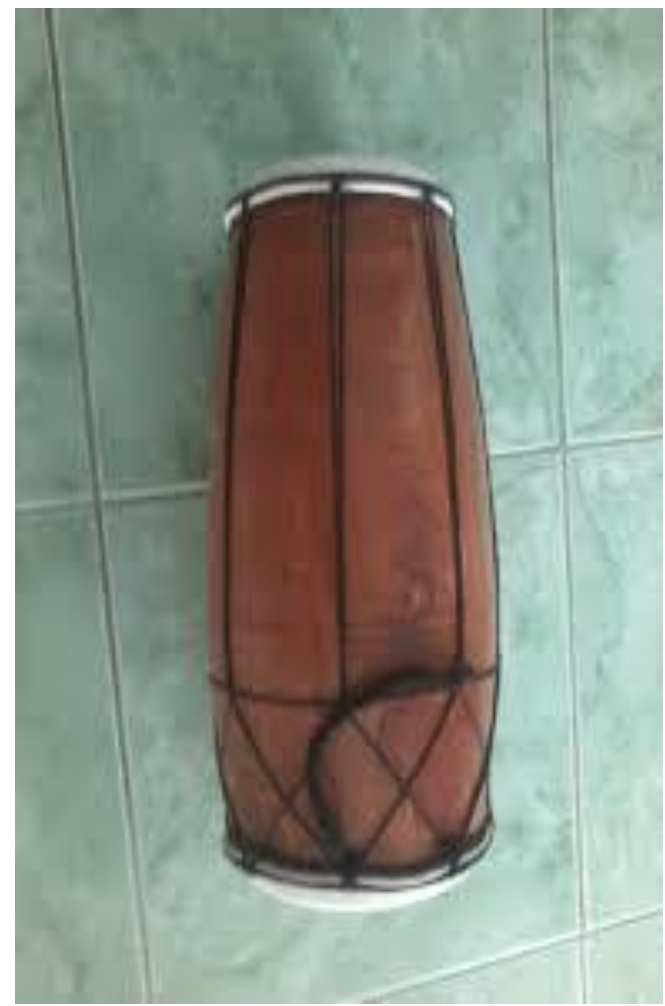

\section{A. Estetika tari Dampeng Aceh Singkil}

Estetika gerak pada tari Dampeng tidak hanya dalam gerak melainkan busana, alat musik, dan syair. Tari ini turun temurun ditarikan oleh masyarakat Aceh Singkil dalam penyambutan hari besar, dan perkawinan masyarakat Aceh Singkil. Tari dampeng juga memiliki estetika didalam busana yaitu pakaian dengan warna-warna tegas dan lembut, warna pakaian tersebut juga memiliki karakter. Itu semua bukti kecintaan mereka 


\section{PENUTUP}

\section{A. Kesimpulan}

1. Tari Dampeng berasal dari seorang pendatang yang berasal dari Minangkabau untuk berdagang ke Singkil, dan menetap di Singkil. Migrasi etnis ini lebih di dorong oleh faktor dagang. Orang Padang terkenal sebagai pedagang ulung dan gigih. Banyak perdagang membawa barang kebutuhan penduduk yang diminati oleh masyarakt singkil.

2. Musik iringan pada dampeng merupakan musik syair dan internal yang berasal dari nyanyian dan bebrapa alat musik.

3. Busana yang digunakan penari pada dampeng terdiri dari baju tangan panjang warna putih, celana panjang warna hitam atau putih, kain sarung setengah tiang (disebut lunggi), dan attribut lainnya seperti tali pinggang, tutup kepala (sebelit pinder) dari kain persegi empat yang dilipat dan diikat keliling kepala. Sedangkan salah satu topinya mencuat ke atas, di bagian belakang kepala. Sedangkan salah satu topinya mencuat ke atas, di bagian belakang kepala. Dalam busana tari Dampeng memakai perpaduan beberapa warna yang

B. Saran

1. Masyarakat Singkil untuk menjaga, mengembangkan serta melestarikan tari-tarian yang berada pada masyarakat Muara Pea khususnya di Kabupaten Aceh Singkil.

2. Diharapkan kepada masyarakat Muara Pea khususnya kepada pemerintah daerah agar senantiasa memperkenalkan berbagai tari-tarian kepada masyarakat luas baik lokal maupun diluar daerah dan mengadakan pertunjukkan kesenian dampeng agar dapat memahami keseniaan Singkil baik secara bentuk geraknya hingga makna yang ingin disampaikan akan tersampaikan kepada penikmat.

3. meningkatkan kepedulian terhadap kesenian daerah, berarti telah menyelamatkan anak cucu 
kita dari pengaruh budaya luar yang akan merusak budaya sendiri.

4. Semoga penelitian ini dapat memberikan pengetahuan baru bagi masyarakat Muara Pea bagaiman Nilai Estetika Pada Tari Dampeng Kabupaten Aceh Singkil.

\section{DAFTAR PUSTAKA}

Anwar, Rishan, Hasibuan. 2009.

Keberadaan Tari CengkokCengkok pada Masyarakat Labuhan Batu Induk. Skripsi Sendratasik. Universitas Negeri Medan.

Anderson. 1974. Antropologi Tari. Bandung: Press STSI.

Hadi. Y. 1984. Sosiologi Tari. Yogyakarta: Pustaka.

Nettl, 1973.Pewarisan kebudayaan melalui mulut ke mulut dapat menciptakan hasil kebudayaan musik. Bandung : Balai Pustaka.

Nugrahaningsi. Tari identitas dan eksistensi, Medan : Unimed Press.
Junianda, Riska.2015. Etika Dan Nilai Estetika Tari Rapa'i Geleng Pada Masyarakat Aceh Barat Daya, Medan. Skripsi Sendratarik. Universitas Negeri Medan.

Purba, Ana. 2014. Analisis Musikal Dampeng Pada Upacara Adat Perkawinan, Medan : Unversitas Sumatera Utara.

Rochmat, Saefur. 2009. Ilmu Sejarah dalam Perspektif Ilmu Sosial, Yogyakarta: Graha Ilmu.

S. Praja, Juhaya,2008. Aliran-aliran Filsafat dan Estetika, Prenada Media Jakarta.

Soedarsono, 1978, Djawa Bali: Dua Pusat Perkembangan Damartunggi Tradisional Di Indonesia. Yogyakarta: Gadjah Mada Univessitas Press.

Sumandiyo. 2005. Antropologi Tari. Bandung: Press STSI 
Sumandiyo. 1966. Antropologi Tari.

Bandung: Press STSI

Sony Dharsono, 2007. Estetika.

Bandung: Rekayasa Sains

Bandung.

Westra, Pariata. 1981. Teori dan

Metodologi Sastra. Jakarta:

Sinar Harapan.

Yunus, Ahmad. 1986. Ensiklopedi

Musik dan Tari Daerah

Istimewa Aceh. Banda Aceh.

Ace 